\title{
Food consumption patterns and their effect on water requirement in China
}

\author{
J. Liu ${ }^{1}$ and H. H. G. Savenije S $^{2,3}$ \\ ${ }^{1}$ Swiss Federal Institute of Aquatic Science and Technology (Eawag), Ueberlandstrasse 133, P.O. Box 611, CH8600, \\ Duebendorf, Switzerland \\ ${ }^{2}$ UNESCO-IHE, Delft, The Netherlands \\ ${ }^{3}$ Delft University of Technology, P.O. Box 5048, 2601 DA, Delft, The Netherlands
}

Received: 24 October 2007 - Published in Hydrol. Earth Syst. Sci. Discuss.: 4 January 2008

Revised: 15 May 2008 - Accepted: 15 May 2008 - Published: 11 June 2008

\begin{abstract}
It is widely recognized that food consumption patterns significantly impact water requirements. The aim of this paper is to quantify how food consumption patterns influence water requirements in China. The findings show that per capita water requirement for food (CWRF) has increased from $255 \mathrm{~m}^{3} \mathrm{cap}^{-1} \mathrm{y}^{-1}$ in 1961 to $860 \mathrm{~m}^{3} \mathrm{cap}^{-1} \mathrm{y}^{-1}$ in 2003, largely due to an increase in the consumption of animal products in recent decades. Although steadily increasing, the CWRF of China is still much lower than that of many developed countries. The total water requirement for food (TWRF) has been determined as $1127 \mathrm{~km}^{3} \mathrm{y}^{-1}$ in 2003. Three scenarios are proposed to project future TWRF, representing low, medium, and high levels of modernization (S1, S2, and S3, respectively). Analysis of these three scenarios indicates that TWRF will likely continue to increase in the next three decades. An additional amount of water ranging between 407 and $515 \mathrm{~km}^{3} \mathrm{y}^{-1}$ will be required in 2030 compared to the TWRF in 2003. This will undoubtedly put high pressure on China's already scarce water resources. We conclude that the effect of the food consumption patterns on China's water resources is substantial both in the recent past and in the near future. China will need to strengthen "green water" management and to take advantage of "virtual water" import to meet the additional TWRF.
\end{abstract}

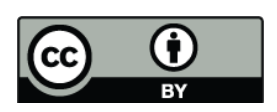

Correspondence to: J. Liu

(water21water@yahoo.com)

\section{Introduction}

Besides population growth and externalities of uncontrolled economic growth, water scarcity is more and more recognized as a major threat to sustainable development (Koudstaal et al., 1992; Postel et al., 1996; Vörösmarty et al., 2000; Oki and Kanae, 2006). While water stress is often a direct result of population growth and economic development, this paper shows that changing consumption patterns may potentially become the main cause of water scarcity. Currently, approximately one third of the world's population lives in countries suffering water stress (Oki and Kanae, 2006). Many authors have projected that a large share of the world's population - up to two-thirds - will be affected by water scarcity over the next decades (Shiklomanov, 1991; Raskin et al., 1997; Seckler et al., 1998; Alcamo et al., 2000; Vörösmarty et al., 2000; Oki and Kanae, 2006).

The problem of water scarcity, in essence, originates from insufficient water for the production of food. Almost $90 \%$ of an individual's water requirement is needed for food production (Savenije, 2000). As a general rule, about 1$2 \mathrm{~m}^{3}$ of water is required to produce $1 \mathrm{~kg}$ of cereal (Allan, 1998; Yang et al., 2003). More water is needed to produce one kilogram of meat. For example, it takes about $13.5 \mathrm{~m}^{3}$ of water to produce $1 \mathrm{~kg}$ of beef in California (Rijsberman, 2006). This means that the water requirement for consuming $1 \mathrm{~kg}$ of beef is equivalent to almost three-fourths of the recommended human's annual basic water requirement for drinking, human hygiene, sanitation, and modest household needs for preparing food (i.e. 50 liters $\mathrm{cap}^{-1} \mathrm{day}^{-1}$, or $18 \mathrm{~m}^{3} \mathrm{cap}^{-1} \mathrm{y}^{-1}$ ) (Gleick, 1996). 
A human being "eats" thousands of liters of water each day; however, the exact amount largely depends on food consumption patterns. Renault and Wallender (2000) estimated that a typical American diet requires twice as much water as a vegetarian diet with the same nutritional intake. Unraveling the effects of various food consumption patterns on water requirement help formulate appropriate water and food policies.

In water resources management it is important to make a distinction between "blue" and "green" water resources (Falkenmark, 2003). Green water is essentially the rainfall that (after infiltration in the unsaturated zone) is directly consumed by plants to produce biomass. Blue water is the water that occurs in water bodies and groundwater, which can be used for irrigation. Most of the global food production relies on "green" water (rainfed agriculture). Liu (2007) computed that $81 \%$ of the global consumptive water use for crop production is green water and that the world water trade in the form of agricultural products ("virtual" water trade as defined by Allen, 1998) relies for $90 \%$ on green water. Although most of the global concerns on water scarcity relate to blue water, it is imperative to study water scarcity in the context of blue and green water interaction, and to consider the partitioning of rainfall into blue and green water, including their spatial and temporal patterns.

This paper aims to quantitatively examine the effects of food consumption patterns on water requirements in China. However, the conclusions of this study range beyond the China case. The developments we observe in China may be of gigantic proportions compared to other countries, but similar developments can be expected in other developing countries and the world at large. The changing food consumption patterns will drastically affect the partitioning between green and blue water and influence the virtual water trade worldwide.

China has been selected for three reasons. First, with a population of about 1.3 billion, China feeds the largest number of consumers in the world; second, in the major food production area, or the North China Plain, blue water resources are only $500 \mathrm{~m}^{3} \mathrm{cap}^{-1} \mathrm{y}^{-1}$ (MWR, 2005). The constraint of water scarcity on food production has led to growing concerns regarding China's food production, food security, and their impacts on the global food market (Liu et al., 2007c); third, China has experienced fast economic growth with an annual GDP growth rate of $8 \%$ over the past two decades; the highest rate in recent world history. Consumers' income has risen substantially, resulting in a rapid dietary change towards more meat consumption (FAO, 2006; Du et al., 2004). The shift in food consumption patterns will undoubtedly have profound effects on water requirements, but in-depth analysis on these effects is rarely found in literature.

\section{Concept, method and data sources}

\subsection{Food requirements at three scale levels}

In this paper, food requirements are classified into three levels of scale: the basic level, the subsistence level and the cultural level, as suggested by Gerbens-Leenes and Nonhebel (2002). At the basic level, food requirements are only sufficient to prevent starvation, but one may suffer from malnutrition in the long run because many essential nutrients are lacking. At this level, the main purpose of food intake is to provide enough energy for basic survival and physical activity. At the subsistence level, food requirements are based on a selected number of nutrient-dense foods recommended that enable one to lead a healthy life over an entire life span. At the cultural level, food requirements correspond to the actual consumption pattern, which is embedded in different types and quantities of food and their combination in different dishes or meals. In order to analyze food requirements at the cultural level, food items have been grouped in six categories:

1. cereals and starchy roots (including rice, wheat, maize, other cereals, potatoes and other starchy roots);

2. sugar and sweeteners;

3. oil crops and vegetable oils;

4. vegetables and fruits;

5. alcoholic beverages; and

6. animal products (including beef, pork, poultry, mutton and goat, fish and seafood, eggs, milk, animal fats).

In 2003, these foods accounted for $98 \%$ of both the total food consumption in weight and the total calorie intake (FAO, 2006).

\subsection{Virtual water content}

The virtual water content (VWC) can be defined as the volume of water used to produce a unit of product at the place where the product is actually produced, or alternatively as the volume of water that would have been required to produce the product in the place where the product is consumed (Chapagain and Hoekstra, 2004). In China, food consumption mainly originates from domestic food production. Food imports are marginal compared to domestic production. For example, in 2003, the imports of cereals and meat were only amounted to about $3 \%$ of the domestic production in weight (FAO, 2006). Due to the small share of food import, the VWC values are determined on the basis of China's specific production conditions. Hence, the first definition of VWC is used in this study. Strictly speaking, the first definition does not imply "virtual" water trade in the literal sense. Hoekstra and Chapagain (2007) used the term of "water footprint" for 
Table 1. Virtual water content and energy water productivity for mostly consumed food items.

\begin{tabular}{|c|c|c|c|c|}
\hline Food Items & & Virtual water content $\left(\mathrm{m}^{3} \mathrm{~kg}^{-1}\right)$ & Energy content $\left(\mathrm{kcal} \mathrm{kg}^{-1}\right)$ & Energy water productivity $\left(\mathrm{kcal} \mathrm{m}^{-3}\right)$ \\
\hline \multicolumn{5}{|l|}{ Cereals and Roots } \\
\hline Rice & & 1.31 & 3625 & 2770 \\
\hline Wheat & & 0.98 & 2633 & 2701 \\
\hline Maize & & 0.84 & 2872 & 3403 \\
\hline Other cereals & $\dagger$ & 1.24 & 2709 & 2185 \\
\hline Potatoes and other starchy roots & $\ddagger$ & 0.23 & 699 & 3107 \\
\hline Sugar and Sweeteners & $\S$ & 1.02 & 3481 & 3423 \\
\hline \multicolumn{5}{|l|}{ Oil crops and Vegetable oils } \\
\hline Soybeans and other oil crops & $\|$ & 3.20 & 3314 & 1035 \\
\hline Vegetable oils & II & 5.08 & 8720 & 1715 \\
\hline \multicolumn{5}{|l|}{ Vegetables and Fruits } \\
\hline Vegetables & $\#$ & 0.19 & 188 & 995 \\
\hline Fruits & $\dagger \dagger$ & 0.50 & 413 & 834 \\
\hline \multicolumn{5}{|l|}{ Animal products } \\
\hline Beef & & 12.56 & 2021 & 161 \\
\hline Pork & & 4.46 & 3500 & 785 \\
\hline Poultry & & 2.39 & 1708 & 715 \\
\hline Mutton and goat meat & $\ddagger$ & 4.50 & 2005 & 446 \\
\hline Fish and sea food & & 5.00 & 497 & 99 \\
\hline Eggs & & 3.55 & 1455 & 410 \\
\hline Milk & & 1.00 & 670 & 670 \\
\hline Animal fats & & 4.00 & 7080 & 1770 \\
\hline Alcoholic beverages ${ }^{\S}$ & & 0.18 & 490 & 2768 \\
\hline
\end{tabular}

$\dagger$ based on data for sorghum

$¥$ based on data for potatoes

$\S$ based on data for refined sugars

II based on data for soybeans

II based on data for soybean oil

\# based on data for tomatoes

$\dagger \dagger$ based on data for apples

$\$$ based on average data for goat meat and sheep meat

$\S \S$ based on data for beer

Sources: virtual water content (VWC) of cereals, soybean, vegetables and fruits from Liu et al. (2007c); VWC of fish and seafood from Zimmer and Renault (2003); VWC of other food items from Chapagain and Hoekstra (2004); Energy content of all food items from FAO (2006).

the first meaning. Hence, the term of VWC in this paper is equivalent to the term of "water footprint" in Hoekstra and Chapagain (2007).

VWC of a crop is generally calculated by dividing consumptive water use (or the sum of crop transpiration and soil evaporation during the crop growing period, in $\mathrm{m}^{3} \mathrm{ha}^{-1}$ ) with crop yield (in $\mathrm{kg} \mathrm{ha}^{-1}$ ) (Liu et al., 2007b) .VWC of an animal at the end of its life span is generally calculated as the total volume of water that was used to grow and process its feed, to provide its drinking water, and to clean its housing and the like (Chapagain and Hoekstra, 2004). Table 1 shows the VWC values for the main food items in China. All these values are obtained from literature except for the VWC of pork. Chapagain and Hoekstra (2004) calculate a VWC value of $2.21 \mathrm{~m}^{3} \mathrm{~kg}^{-1}$ for pork. This value is likely underestimated. In China, to produce $1 \mathrm{~kg}$ of pork, about $4.6 \mathrm{~kg}$ of maize and $1.2 \mathrm{~kg}$ of rough forage are required (Zhang, 2003). The VWC of maize is $0.84 \mathrm{~m}^{3} \mathrm{~kg}^{-1}$ (Table 1), and the VWC of forage is about $0.5 \mathrm{~m}^{3} \mathrm{~kg}^{-1}$ (Zhang, 2003). Hence, the VWC of pork is estimated to be $4.46 \mathrm{~m}^{3} \mathrm{~kg}^{-1}$, which is almost double the value from Chapagain and Hoekstra (2004).

Generally, animal products, oil crops and vegetable oils have relatively high VWC values compared to other food items. Particularly, beef has the highest VWC of $12.6 \mathrm{~m}^{3} \mathrm{~kg}^{-1}$ of all food items. In contrast, vegetables and fruits have the lowest VWC. The VWC values of cereals are between 0.84 and $1.31 \mathrm{~m}^{3} \mathrm{~kg}^{-1}$.

\subsection{Energy water productivity}

Energy water productivity is defined as the energy produced by one unit of water, and is calculated by dividing the energy content of a food crop by its VWC. The data on energy content have been taken from the FAO Food Balance Sheets for China's food consumption in 2003 (FAO, 2006). Cereals and starchy roots have the highest energy water productivity, ranging between $2185 \mathrm{kcal} \mathrm{m}^{-3}$ and $3403 \mathrm{kcal} \mathrm{m}^{-3}$ 
Table 2. Food consumption patterns of China over time.

\begin{tabular}{|c|c|c|c|c|c|c|c|c|c|c|}
\hline \multirow[t]{2}{*}{ Food Items } & \multicolumn{10}{|c|}{ Per capita annual food consumption $\left(\mathrm{kg} \mathrm{cap}^{-1} \mathrm{yr}^{-1}\right)$} \\
\hline & 1961 & 1965 & 1970 & 1975 & 1980 & 1985 & 1990 & 1995 & 2000 & 2003 \\
\hline \multicolumn{11}{|l|}{ Cereals and Starchy roots } \\
\hline Rice & 50 & 72 & 78 & 80 & 84 & 98 & 93 & 91 & 88 & 79 \\
\hline Wheat & 22 & 34 & 34 & 43 & 61 & 78 & 81 & 79 & 74 & 61 \\
\hline Maize & 21 & 18 & 20 & 21 & 26 & 23 & 25 & 19 & 17 & 15 \\
\hline Other cereals & 26 & 25 & 23 & 19 & 15 & 12 & 8 & 5 & 3 & 3 \\
\hline Potatoes and other starchy roots & 112 & 105 & 118 & 109 & 91 & 66 & 59 & 59 & 75 & 74 \\
\hline Sugar and Sweeteners & 2 & 3 & 3 & 3 & 5 & 7 & 8 & 7 & 7 & 8 \\
\hline \multicolumn{11}{|l|}{ Oil crops and Vegetable oils } \\
\hline Soybeans and other oil crops & 5 & 5 & 6 & 5 & 5 & 6 & 6 & 7 & 8 & 7 \\
\hline Vegetable oils & 1 & 2 & 2 & 2 & 3 & 4 & 6 & 7 & 8 & 11 \\
\hline \multicolumn{11}{|l|}{ Vegetables and Fruits } \\
\hline Vegetables & 79 & 57 & 44 & 47 & 49 & 79 & 99 & 148 & 225 & 270 \\
\hline Fruits & 4 & 5 & 5 & 6 & 7 & 11 & 17 & 32 & 43 & 50 \\
\hline \multicolumn{11}{|l|}{ Animal products } \\
\hline Beef & 0.1 & 0.3 & 0.3 & 0.3 & 0.4 & 0.5 & 1 & 3 & 4 & 5 \\
\hline Pork & 2 & 7 & 7 & 8 & 12 & 16 & 20 & 27 & 33 & 35 \\
\hline Poultry & 1 & 1 & 1 & 1 & 2 & 2 & 3 & 7 & 11 & 11 \\
\hline Mutton and goat meat & 0 & 0 & 0 & 0 & 0 & 1 & 1 & 1 & 2 & 3 \\
\hline Fish and sea food & 5 & 5 & 5 & 6 & 5 & 7 & 11 & 21 & 26 & 25 \\
\hline Eggs & 2 & 2 & 2 & 2 & 3 & 5 & 6 & 13 & 16 & 18 \\
\hline Milk & 2 & 2 & 2 & 2 & 3 & 5 & 6 & 8 & 10 & 17 \\
\hline Animal fats & 0 & 1 & 1 & 1 & 1 & 1 & 1 & 2 & 2 & 2 \\
\hline Alcoholic beverages & 1 & 2 & 2 & 3 & 5 & 8 & 13 & 23 & 24 & 27 \\
\hline
\end{tabular}

Sources: FAO (2006)

(Table 1). Animal products generally have much lower energy water productivity than plant products. For instance, beef needs 17 times more water than wheat to supply the same amounts of energy. If the average energy requirement of $2250 \mathrm{kcal} \mathrm{cap}^{-1} \mathrm{day}^{-1}$ is covered by wheat, then $0.8 \mathrm{~m}^{3} \mathrm{cap}^{-1} \mathrm{day}^{-1}$ of water is required. However, if this amount of energy is covered by beef $14 \mathrm{~m}^{3} \mathrm{cap}^{-1}$ day $^{-1}$ is needed.

\subsection{Historical food consumption patterns}

Chinese diets have shifted towards animal products, particularly meat. Meat used to be luxury food in China, and its consumption remained at low levels prior to 1980 . However, meat consumption has risen rapidly, by a factor of 3.7 from 1980 to 2003. The large increase in meat consumption is mainly due to the rapid increase in per capita income, urbanization, and market expansion (Hsu et al., 2002; Huang et al., 1999). In the past four decades, the consumption of rice and wheat increased gradually until it peaked in the late 1990s. Since then, cereal consumption has dropped. The consumption of maize changed little over time, with only a slight decline in recent years. The consumption of starchy roots steadily declined until 1995, and then bounced back in the early 2000s. Another remarkable change was the significant increase in vegetable and fruit consumption. On average, the consumption of fruits and vegetables reached $320 \mathrm{~kg} \mathrm{cap}^{-1} \mathrm{y}^{-1}$ in 2003, which is a fourfold increase compared to that in 1961, and is now the most abundantly eaten food type in weight. The consumption of sugar and sweeteners, oil crops and vegetable oils and alcoholic beverages is also increasing. The historical food consumption of various food items over time is presented in Table 2.

\subsection{Per capita water requirement for food}

Per capita water requirement for food (CWRF) is defined as the amount of water used to produce certain food requirements on a per capita basis. The CWRF is calculated by multiplying the food requirements per food item by the VWC of the corresponding food item and then summing the results for the food categories. Three levels of CWRF (basic CWRF, subsistence CWRF, and cultural CWRF) have been estimated based on the three scale levels of food requirements. The basic CWRF is determined based on two considerations. First, the caloric energy requirements are hypothesized to be met only by the consumption of wheat (Gerbens-Leenes and Nonhebel, 2002); second, according to the Chinese Nutrition Society (CNS), at least 2400 and $2100 \mathrm{kcal} \mathrm{cap}^{-1} \mathrm{day}^{-1}$ of energy is required for male and female Chinese adults, respectively, to carry out light physical activities under healthy living conditions. Thus, the average of $2250 \mathrm{kcal} \mathrm{cap}^{-1} \mathrm{day}^{-1}$ has been used as the recommended energy intake at the basic level. It may be argued that, while wheat is a staple food in the Northern part of China, rice is a more consumed food in the Southern part. However, the energy water productivity of wheat is almost identical to that of rice (Table 1). Hence, the basic CWRF calculated 


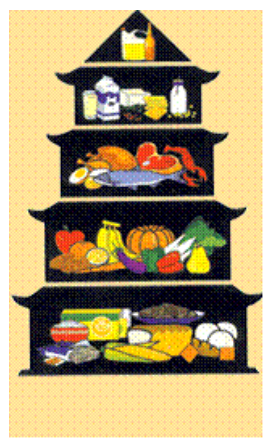

Level 5: fats and oils 25 g/cap/day

Level 4: milk and milk products $100 \mathrm{~g} / \mathrm{cap} /$ day bean and bean products $50 \mathrm{~g} / \mathrm{cap} /$ day

Level 3: meat and poultry $50-100 \mathrm{~g} / \mathrm{cap} / \mathrm{day}$ fish and shrimp 50g; eggs 25 - $50 \mathrm{~g} / \mathrm{cap} /$ day

Level 2: vegetables $400-500 \mathrm{~g} / \mathrm{cap} /$ day fruits $100-200 \mathrm{~g} / \mathrm{cap} / \mathrm{day}$

Level 1: cereals 300 - 500 g/cap/day

Fig. 1. Chinese food guide pagoda from the Chinese Nutrition Society.

with only wheat consumption is justified here. The calculation of subsistence CWRF is based on the recommended daily amounts of food intake from the food guide pagoda of the CNS (http://www.cnsoc.org). The food guide pagoda is available in Fig. 1. According to CNS, $100 \mathrm{~g}$ of milk and milk products are equivalent to $200 \mathrm{~g}$ of fresh milk, and $50 \mathrm{~g}$ bean and bean products are equivalent to $40 \mathrm{~g}$ of soybean. These equivalences are used in the calculation of subsistence CWRF. Further, the consumption ratio of different cereals (in weight) and meat has been assumed identical to the cereal consumption pattern in 2003. The cultural CWRF is calculated based on actual food consumption patterns. Annual consumption of various food items over 1961-2003 is obtained from FAOSTAT (FAO, 2006).

\subsection{Total water requirement for food}

Total water requirement for food (TWRF) is the total amount of water consumed to produce certain food requirements for all the individuals in a country. It is calculated for China by multiplying CWRF by the population. Historical population data have been obtained from FAO (2006) for the period of 1961-2003. TWRF at the basic and subsistence levels have not been calculated, because these two levels are purely hypothetical situations which do not provide any information on the current and future water requirement situation.

\section{Water requirement for food}

\subsection{Historical CWRF}

Basic CWRF is estimated to lie around $300 \mathrm{~m}^{3} \mathrm{cap}^{-1} \mathrm{y}^{-1}$. Subsistence CWRF ranges from 505 to $730 \mathrm{~m}^{3} \mathrm{cap}^{-1} \mathrm{y}^{-1}$. These two numbers correspond to low and high subsistence levels respectively. The low subsistence level is determined by using the lower limits of food consumption for various food groups in Fig. 1, while the high subsistence level is determined by using the upper limits. CWRF at the high sub-

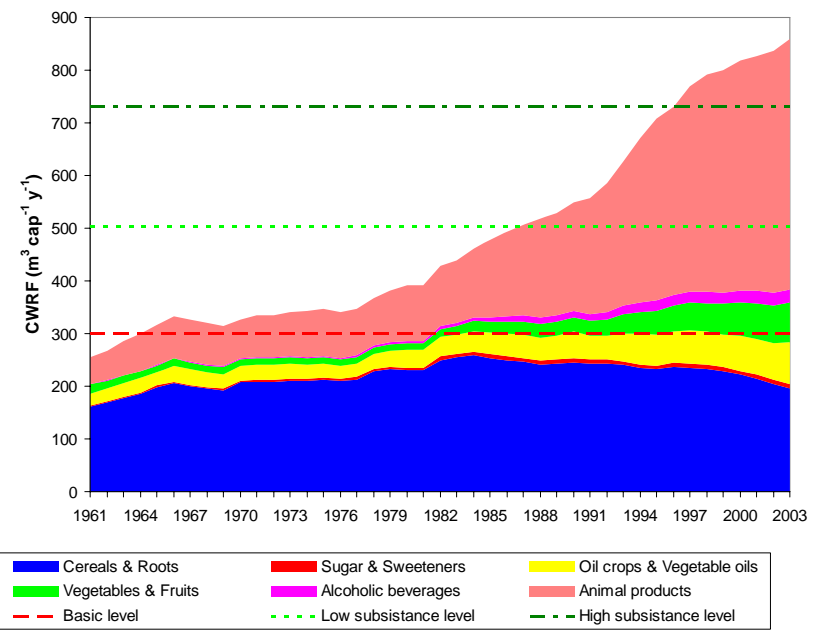

Fig. 2. The per capita water requirement for food (CWRF) at the basic, subsistence and cultural levels. CWRF is calculated based on VWC values of various food items for the year around 2000.

sistence level is more than double the basic CWRF. Figure 2 presents the estimated cultural CWRF from 1961 to 2003, indicating the basic and subsistence CWRF levels.

The cultural CWRF in the early 1960s was lower than the basic CWRF (Fig. 2). The year 1961 is the last year of the so-called "three bad years", which contained a series of calamities that resulted in the deaths of tens of millions directly caused by starvation. In 1961, the Chinese government started to introduce a series of new economic policies known as "readjustment, consolidation, filling-out, and raising standards" to boost agricultural production. Consequently, cereal consumption (particularly wheat and rice consumption) rose steadily, which led to an increase in CWRF from 1961 to 1965. Afterwards, the Cultural Revolution, 1966-1976, which involved devastating social turmoil, had adverse effects on agricultural production. Over this period, cultural CWRF remained close to the basic level. After the Cultural Revolution, China abandoned collective agriculture and in 1978 assigned most agricultural land to families under the household responsibility system. The adoption of this system contributed to technological changes, which played an important role in driving productivity, particularly in the $1980 \mathrm{~s}$ (Liu and Yin, 2004). Between 1978 and 1984, the rise of cultural CWRF was largely due to higher consumption of cereals and starchy roots and animal products. After 1984, consumption of cereals and starchy roots showed a slight decline. The increase in cultural CWRF was mainly caused by higher consumption of animal products, oil crops and vegetable oils, and vegetables and fruits. Cultural CWRF reached low subsistence CWRF in the late 1980s, and then arrived at high subsistence CWRF in the middle 1990s. In 2003, the cultural CWRF reached $860 \mathrm{~m}^{3} \mathrm{cap}^{-1} \mathrm{y}^{-1}$, which is about $18 \%$ higher than the CWRF at the high subsistence level. This is mainly due to meat and fish consumption being 


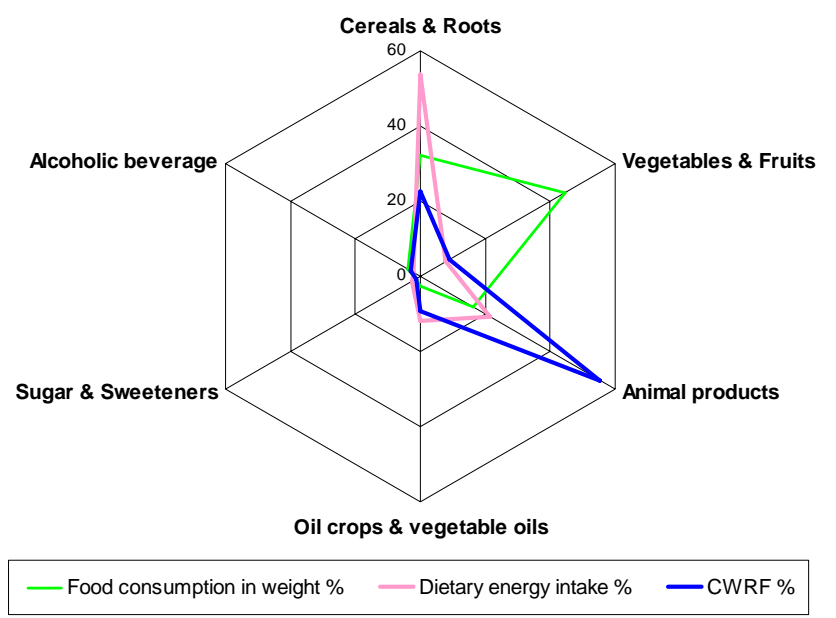

Fig. 3. Sources of food consumption in weight, dietary energy intake and CWRF in 2003. All are presented as the percentage of the total.

higher than the CNS recommended amount by about $50 \%$. The contribution of animal products to CWRF has increased from $20 \%$ to $55 \%$ from 1961 to 2003 . The contribution of cereals and starchy roots decreased from $63 \%$ to $23 \%$ during the same time span. Water requirement for the consumption of both vegetables and fruits and oil crops and vegetable oils steadily increased over time, contributing to $18 \%$ of CWRF in 2003 .

Per capita water requirement for animal products has increased by $33 \%$ since 1996 . In contrast, water requirement for the consumption of non-animal products almost leveled off over this period. Increasing water requirement for vegetables and fruits and oil crops and vegetable oils is almost compensated by decreasing water requirement for cereals and starchy roots.

Water requirements for the consumption of specific food items or categories depend not only on food consumption in weight but also on the VWC of these foods. For instance, even though animal products accounted for only $16 \%$ of total food consumption in weight in 2003, their production required 55\% of the cultural CWRF (Fig. 3). In contrast, vegetables and fruits accounted for $44 \%$ of the total food consumption in weight, but their consumption only resulted in about $9 \%$ of CWRF. The VWC of animal products generally has much higher values than that of vegetables and fruits, as shown in Table 1. As a result, some food items take a disproportional share of the water requirements. Similarly, some food groups have a disproportional share of the dietary energy intake and cultural CWRF (Fig. 3). In this regard, the energy water productivity plays a key role.

It should be pointed out that the VWC values used in this study (Table 1) are based on estimations for the years around 2000. VWC values fluctuate. For example, Xu

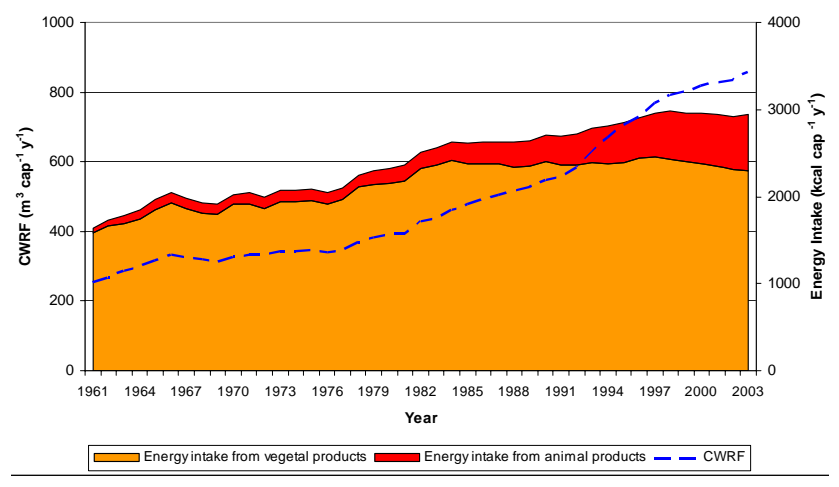

Fig. 4. Relation between energy intake and per capita water requirement for food (CWRF) at the cultural level over 1961-2003.

and Zhao (2001) report that VWC of rice decreased from $4.3 \mathrm{~m}^{3} \mathrm{~kg}^{-1}$ in 1949 to $1.1 \mathrm{~m}^{3} \mathrm{~kg}^{-1}$ in 1996 in Fengqiu County in China. This decrease in VWC is mainly caused by technological innovations including the establishment of water conservation facilities, better soil management, extension of new crop varieties, and a continuous increase in fertilizer application (Xu and Zhao, 2001). Annual VWC values of various food items in China are, unfortunately, rarely available. However, this should not influence the presented analysis, as its main objective is to demonstrate the effect of consumption patterns alone on CWRF, while holding all other variables constant. Therefore, the influence of technological changes has not been included. However, it will be taken into account in the scenario analysis of the future TWRF.

\subsection{Historical cultural CWRF and energy intake}

Cultural CWRF and energy intake has changed at almost equal annual growth rates between 1961 and 1984 (see Fig. 4). They both increased at a rate of $5 \% \mathrm{y}^{-1}$ from 1961 to 1965 , remained almost zero from 1966 to 1976, and increased again at a rate of about $4 \% \mathrm{y}^{-1}$ from 1977 to 1984. Over the period 1961-1984, consumption of animal products hardly varied; and energy intake from animal products remained relatively constant. The variation in total energy intake was mainly caused by changes in the consumption of cereal crops and starchy roots (FAO, 2006). Cereals and starchy roots have similar energy water productivity, resulting in the similar increase rates of cultural CWRF and energy intake.

From 1985 to 1997, however, the CWRF increased much faster than total energy intake. Growth rates of CWRF and total energy intake were $5 \% \mathrm{y}^{-1}$ and $1 \% \mathrm{y}^{-1}$, respectively. The main reason for the faster growth of CWRF was the increase in the consumption of food items with low energy water productivity (e.g. animal products) and less consumption of the food items with high energy water productivity (e.g. starchy roots). Although total energy intake from nonanimal products only increased slightly, consumption of var- 
ious plant products changed. Consumption of cereals and starchy roots declined, while consumption of vegetables and fruits increased significantly, thus causing a further growth of CWRF.

Since 1997, energy intake has slightly declined. The decrease in energy intake from cereals and starchy roots outweighed the increase in energy intake from animal products. Lower energy water productivity of animal products led to a further increase in CWRF.

\subsection{Comparison with other regions}

In order to assess regional variation, cultural CWRF values have been estimated in different regions based on the food consumption patterns in 2003 and the VWC values shown in Table 1. The regions analyzed are the European Union (the 15 member countries as a whole prior to the accession of the candidate countries on 1 May 2004, termed as EU15 here), USA, Japan, South Korea, developing countries as a whole (Developing), developed countries as a whole (Developed), and the world at large (World). Developed and developing countries have been distinguished according to the classification by the Food and Agriculture Organization of the United Nations (FAO, 2006).

Cultural CWRF values vary significantly among regions (Fig. 5). The largest value is for the USA $\left(1820 \mathrm{~m}^{3} \mathrm{cap}^{-1} \mathrm{y}^{-1}\right)$, and the smallest for the developing countries $\left(685 \mathrm{~m}^{3} \mathrm{cap}^{-1} \mathrm{y}^{-1}\right)$. The CWRF of China is slightly higher than that of the world average, but is much lower than that of developed countries, particularly EU15 and the USA (Fig. 5). Two other Asian countries, Japan and South Korea, have a cultural CWRF value of $26 \%$ and $30 \%$ higher than China, respectively. The relatively low CWRF of China is mainly due to lower consumption of animal products. For example, in the USA, the consumption of animal products corresponds to almost $1227 \mathrm{~m}^{3} \mathrm{cap}^{-1} \mathrm{y}^{-1}$ of water. This volume alone is much larger than the CWRF of China. Additionally, developed countries also consume more sugar and sweeteners and alcoholic beverages than China. Water requirements for the consumption of cereals and starchy roots hardly vary among regions.

In the near future, dietary changes in China, directed towards higher consumption of animal products, will continue to bear on water requirements. If China shifts towards the American level of animal product consumption, the cultural CWRF will more than double the present level. Similarly, if consumption patterns in developing countries would shift towards the affluent diets of western countries, the CWRF values would rise up to a three fold increase. Such a change in food consumption pattern would play a much greater role in increasing water requirements than population growth.

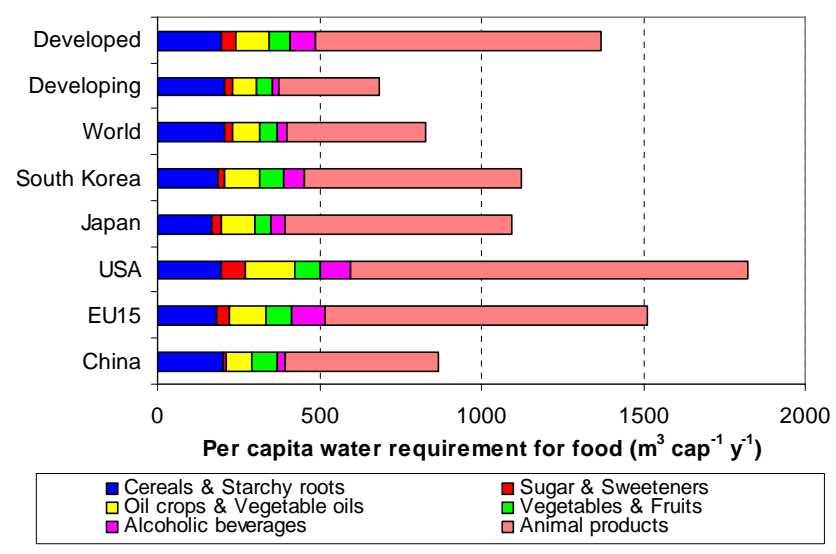

Fig. 5. Per capita water requirement for food (CWRF) at the cultural level in 2003 in different regions. CWRF in all regions is estimated with VWC of individual food items determined on the basis of China's specific production conditions.

\subsection{CWRF and TWRF in the future}

The TWRF is estimated at $1127 \mathrm{~km}^{3} \mathrm{y}^{-1}$ in China in 2003. The future levels of CWRF and TWRF largely depend on food consumption patterns and future population. In addition, technological changes will also have a profound impact on both CWRF and TWRF via their influence on VWC. Accurate estimation of future food consumption patterns is very difficult. Several studies estimated future meat consumption, such as $30-50 \mathrm{~kg} \mathrm{cap}^{-1} \mathrm{y}^{-1}$ for 2025 (Heilig, 1999), $51.3 \mathrm{~kg} \mathrm{cap}^{-1} \mathrm{y}^{-1}$ for 2020 (World Bank, 1997), and $63 \mathrm{~kg} \mathrm{cap}^{-1} \mathrm{y}^{-1}$ for 2020 (Christopher et al., 1998). In 2003, meat consumption reached $55 \mathrm{~kg} \mathrm{cap}^{-1} \mathrm{y}^{-1}$ (FAO, 2006) demonstrating that the first two studies already underestimated present consumption. Hence, future CWRF estimation based on these projections would lead to large errors. In this paper, future CWRF values have been determined based on the general trend of historical food consumption patterns of individual food items. The baseline annual growth rates of food consumption of individual food items are calculated based on the food consumption pattern over 1998-2003. Future growth rates are analyzed under three scenarios based on the baseline annual growth rates.

Technological changes may affect VWC values. According to Liu et al. (2007b), crop water productivity (CWP) for different crops, or the inverse of VWC, has a strong linear relation with crop yield. The linear relation exists even when setting the intercept at zero $\left(r^{2}=0.77\right)$. This relation allows fixing the annual growth rate of the CWP at the annual growth rate of the crop yield. In this way, we can estimate the future VWC if the effects of technological change on crop yield are known. The average annual growth rates of crop yield for individual crops over 1998-2003 are set as baseline annual growth rates. To reduce the annual variation 3 -year averages are used in the calculation. For example, the 

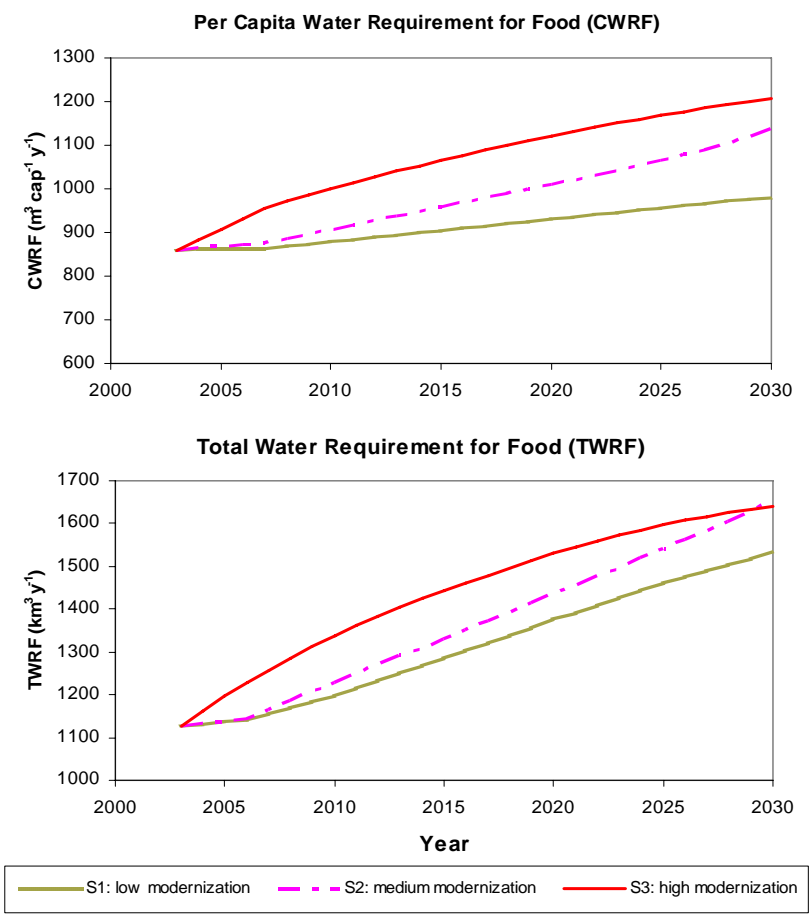

Fig. 6. Per capita water requirement for food (CWRF) and total water requirement for food (TWRF) in 2003-2030 under three scenarios.

average yield between 2002 and 2004 is treated as the yield in 2003. Future annual growth rates of crop yield are assumed in three scenarios based on the baseline growth rates. It needs to be pointed out that the linear relation between CWP and crop yield may not always hold true, for example, when drought tolerant crop varieties are introduced (e.g. replacement of paddy rice by aerobic rice). However, the relation provides a simple and often reliable way to project CWP in the future.

The relation between technological changes and VWC of animal products is more complex. Some animals such as pigs, goats, and chicken largely rely on grain feed (mainly maize), while animals such as cattle and cows mainly feed on pasture land. For example, about $80 \%$ of the VWC of pork is related to maize, and the remaining $20 \%$ is related to rough forage (Zhang, 2003). In contrast, only 3\% of VWC of beef is related to grain, while the remaining is related to green grass (Zhang, 2003). Crop yields of rough forage and grasses over time are commonly not reported in China. It is expected that the yields of rough forage and grasses are mainly affected by local climate and soil conditions, and that they are not significantly influenced by technological innovations. As a result, we assume that the annual growth rates of the VWC of pork, poultry, mutton and goat meat, eggs, and animal fats (mainly fats of pigs are consumed in China) are equal to the annual growth rate of the VWC of maize. The VWC values of all other animal products are assumed constants over time.

The projection of China's future population has been taken from the 2006 revision of World Population Prospects (United Nation, 2006). Here we use the period prior to 2030 for scenario analysis. According to the medium variant of the UN's projection, China's population may reach its maximum in 2030 after which it is expected to decline. Thus, in the nearest future China will face its greatest challenge in meeting domestic food demand. To analyze the TWRF in the period of 2004-2030, three scenarios have been developed.

\section{Low modernization scenario (S1)}

The annual growth rates of food consumption of individual food items slow down to $50 \%$ of the baseline annual growth rates of food consumption. Technological innovations increase yields of individual crops, but the annual growth rates of crop yield are only $50 \%$ of the baseline annual growth rates for the corresponding food items. Population growth follows the high variant of the UN population projection.

\section{Medium modernization scenario (S2)}

The annual growth rates of food consumption of individual food items remain the same as the baseline annual growth rates. The baseline annual growth rate of crop yield of each food item will continue over the next three decades due to technological innovations. Population growth follows the medium variant of the UN population projection.

\section{High modernization scenario (S3)}

The annual growth rates of food consumption of individual food items are 50\% higher than the baseline annual growth rates. Technological innovation increases yield, and the annual growth rates of crop yield of individual crops are $50 \%$ higher than the baseline annual growth rates. Population growth follows the low variant of the UN population projection.

The results of future CWRF and TWRF scenarios S1-S3 are presented in Fig. 6. Under S1, the shift in food consumption patterns alone will result in $22 \%$ more TWRF in 2030 compared to that in 2003, while population growth alone will lead to $19 \%$ more TWRF. Both factors combined increase the TWRF by $45 \%$ over $2003-2030$. Technological changes decrease the VWC by about $6 \%$ for all the food items as a whole. As a result, TWRF reaches $1534 \mathrm{~km}^{3} \mathrm{y}^{-1}$ in 2030 , about $36 \%$ higher than in 2003. Without considering technological changes, CWRF will arrive at $1043 \mathrm{~m}^{3} \operatorname{cap}^{-1} \mathrm{y}^{-1}$ in 2030, slightly lower than the CWRF in Japan at current level (in 2003). After taking technological changes into account, CWRF will arrive at $981 \mathrm{~m}^{3} \mathrm{cap}^{-1} \mathrm{y}^{-1}$ in 2030.

Under S2, the shift in food consumption and population growth will lead to $46 \%$ and $11 \%$ increase in 2030 compared 
to 2003 , respectively. Both factors combined will increase the TWRF by $62 \%$. Technological innovation alone will decrease the VWC by $9 \%$ for all the food items as a whole. As a result, TWRF arrives at $1658 \mathrm{~km}^{3} \mathrm{y}^{-1}$ in 2030, about $47 \%$ higher than in 2003. Without considering technological changes, CWRF will arrive at $1249 \mathrm{~m}^{3} \mathrm{cap}^{-1} \mathrm{y}^{-1}$ in 2030, about $10 \%$ higher than the CWRF in South Korea at current level (in 2003). After taking technological changes into account, CWRF will be $1137 \mathrm{~m}^{3} \mathrm{cap}^{-1} \mathrm{y}^{-1}$.

Under S3, the shift in food consumption patterns and population growth will result in $56 \%$ and $4 \%$ increase compared to 2003 , respectively, whereas both factors combined increase the TWRF by $62 \%$. Technological innovation decreases the VWC by $10 \%$ for all the food items as a whole. As a result, TWRF arrives at $1641 \mathrm{~km}^{3} \mathrm{y}^{-1}$ in 2030, about $46 \%$ higher than in 2003. Without considering technological changes, CWRF will arrive at $1342 \mathrm{~m}^{3} \mathrm{cap}^{-1} \mathrm{y}^{-1}$ in 2030, almost reaching the average CWRF in developed countries at current level (in 2003). After taking technological changes into account, CWRF will be $1208 \mathrm{~m}^{3} \mathrm{cap}^{-1} \mathrm{y}^{-1}$.

Whatever scenario is used, the TWRF will continue to increase in the next three decades. An additional amount of water ranging between 407 and $515 \mathrm{~km}^{3} \mathrm{y}^{-1}$ will be required compared to the TWRF in 2003. This is a substantial increase, which amounts to $182-230 \%$ of current consumptive irrigation water use (MWR, 2005). The analysis also suggests that the shift in food consumption pattern will contribute more to the growth of the TWRF than population growth, especially under S2 and S3.

\section{Conclusions}

The findings in this paper show that per capita water requirement for food (CWRF) has increased over three times from 1961 to 2003, largely due to an increase in the consumption of animal products in recent decades. The scenario analysis indicates that future total water requirement for food (TWRF) will likely continue to increase in the next three decades. Even in the low modernization scenario, the shift in food consumption patterns together with population growth may lead to an additional amount of required water of over $400 \mathrm{~km}^{3} \mathrm{y}^{-1}$ in 2030, even after taking technological advances into consideration. This will undoubtedly put high pressure on China's already scarce water resources.

There are three sources of water that can be managed to meet the additional TWRF requirements. The first source is blue water, which is defined as the water in rivers, lakes, reservoirs, ponds and aquifers (Falkenmark, 2003). For food production, blue water means irrigation. However, increasing water scarcity and competition from other sectors have put agricultural blue water use under great pressure. There has been a reallocation of irrigation water to industrial and domestic sectors, and environmental water needs are given more and more weight (Yang and Zehnder, 2001). In
China, irrigation water use declined by $15 \%$ over $1997-2003$ (MWR, 2005). It is difficult to allocate more blue water to future domestic agricultural production.

The second source of water is green water. Green water refers to the water coming from precipitation, stored in the unsaturated soil, and taken up by plants as transpiration (Savenije, 2000). Green water accounts for $73 \%$ of the consumptive water use for domestic crop production in China (Liu, 2007), and likely constitutes more than $90 \%$ of the water used for the production of animal products. In particular grazing production systems use mostly green water, in which water has almost zero opportunity cost. Although important, green water is often ignored by water managers, largely due to the difficulty to assess or manage it and its low opportunity cost (Liu, 2007). Capturing more green water can be achieved by expanding agricultural land areas, water conservation and by more effectively utilizing local rainfall. Expanding agricultural land areas will not likely be feasible in China. Recent land use trends show a reallocation of agricultural land to other uses (Tan et al., 2005). Effective rainfall management seems a more feasible option to increase the future water supply. Rockström et al. (2003) demonstrated that rainwater harvesting is a promising approach for green water management in the semi-arid tropics of Asia and Africa. Rainfall harvesting has been adopted in the past by many households in the semi-arid areas in China to provide water storage for both irrigation and household usage (Zhao et al., 1995). So far, it has been practiced in 15 provinces, mainly in the North, Northwest, and Southwest China. The potential of additional water supply through rainwater harvesting has never been quantitatively assessed for China.

Obviously a policy towards more rainwater harvesting will affect the partitioning of the rainfall between blue, green and white water. White water is the part of the rainfall that returns to the atmosphere directly by evaporation from intercepted water, and it is not available for blue or green water use (Savenije, 2000). This is the "unproductive" water that can amount to a considerable part of the water balance depending on local conditions (Savenije, 2004), depending primarily on the rainfall distribution over the season and land use. Rainwater harvesting aims at reducing the white (unproductive) use of water and increasing the green water availability by enhancing infiltration from water which would otherwise run off as surface runoff. In doing so, green water management affects the rainwater partitioning of the hydrological cycle in a way that the infiltration increases, the surface runoff (and related erosion) decreases, and as a result the transpiration and percolation increases. For the availability of blue water resources, rainwater harvesting implies a general reduction of blue water, due to a reduction of fast runoff, but it may also lead to an increase of delayed runoff from groundwater seepage. In economic terms the gain in delayed runoff and the related erosion reduction may offset the loss of overall runoff. Clearly the water resources implications of such a green water policy need to be studied in more detail in a river 
basin context, and particularly the upscaling effect of rainwater harvesting measures, which is also the subject of study in other parts of the world and particularly Africa (e.g. Rockström et al., 2004; Ngigi et al., 2006; Makurira et al., 2007).

The third source of water is virtual water import. Virtual water describes the amount of water consumed in the production process of a product (Allan, 1998). The concept of virtual water import implies that water scarce countries could mitigate water scarcity by importing water intensive food (Chapagain et al., 2006; Hoekstra and Hung, 2005; Yang et al., 2003; Liu et al., 2007b; Liu and Savenije, 2008). Based on the food items looked at in this study, it is estimated that China had a total net virtual water import of $81 \mathrm{~km}^{3} \mathrm{y}^{-1}$ in 2003 , equivalent to $8 \%$ of the TWRF. The virtual water strategy has not been consciously used by the Chinese government, largely due to its emphasis on the principle of selfsufficiency in food supply (Liu et al., 2007c). With intensified water scarcity, China's decision makers may have to consider loosening its stance on the self-sufficiency principle and, thereby, taking advantage of virtual water import through the trade of water-intensive foods (Liu and Savenije, 2008).

To conclude, the additional TWRF triggered by the shift of food consumption patterns and population growth will impose high pressure on China's finite water resources. Amongst the other options, two seem feasible to meet the additional water required for food consumption, namely effectively rainfall management and increased virtual water imports. Both options need further study to provide realistic estimates of their potential contribution to mitigating China's water scarcity. Besides, other important ways of decreasing VWC and hence decreasing TWRF could include crop yield improvement through agricultural research and formulation of appropriate agricultural policies. These two options are particularly important given China's continued significant investment in agricultural technology research in the past decades, the food self-sufficiency policy, and the increasing emphasis on reducing the development gap between rural and urban areas, which leads to agricultural policy reform.

A further cause of concern is the high reliance on fertilizers in the high technology development scenario. Particularly the high dependency on phosphate, a mined and finite resource, is worrying. Global phosphate resources are rapidly depleting and without adequate recycling of nutrients (particularly urine) phosphate may become one of the most critical resources for the increasing world population (Steen, 1998; Gumbo, 2005).

Since the requirement of additional water largely depends on food consumption patterns, it is theoretically possible to reduce the additional water requirement by consuming lower amounts of food items with high VWC, such as animal products. Fish could serve as an alternative to meat as a source of protein. Production of sea fish does not require freshwater; hence, replacement of part of meat with sea fish can also save freshwater. Zimmer and Renault (2003) estimated that the VWC of fish is $5 \mathrm{~m}^{3} \mathrm{~kg}^{-1}$ (see Table 1). However, this seems like an over-estimation of the fresh water requirement of fish. Fish from aquaculture requires fresh water in the form of fish feeding and the filling and flushing of fish ponds (which is recycled). Since fish feed mainly relies on the use of manure and offal (a byproduct of animal production), the VWC of fish is not expected to be high. Although detailed computations of virtual water use by fish cultivation are beyond the scope of this paper, it is likely that replacement of meat with fish may imply considerable fresh water savings.

In general, food consumption patterns are closely related to increasing affluence. However, awareness-raising may play a role in affecting the food preference of China's population. Currently, China's meat consumption has exceeded the recommended amounts by the CNS. In addition, some authors have argued that the contemporary Chinese diet shifts may be detrimental to health, by introducing higher incidence of diet-related diseases (Du et al., 2004). Raising public awareness and encouragement of a diet recommended by the CNS may help mitigate the future water scarcity problem in China.

In this paper, we analyze the effect of food consumption patterns on water requirement in an aggregated way for China. It is well known that water scarcity is often a regional problem particularly in the northern part of China, water being more abundant in the southern part of the country. Hence, a more detailed region analysis is useful to compare water requirement with local water resources. However this kind of analysis is limited by data availability. Firstly, regional consumption data for detailed food items are generally lacking. As far as we know, FAO is the best source that provides consumption data for such detailed food items used in this paper. In the Chinese statistical yearbooks, consumption data are generally reported by treating a number of food items as food groups. Examples are consumptions of grain, meat and poultry, eggs, and vegetables. Second, VWC often differs in various locations even for a same food item due to different climatic conditions, soil parameters, and agriculture management, but data on VWC are generally not available at sub-national levels for most food items. Liu et al. (2007a) estimate crop water productivity, or the inverse of VWC, for wheat in China with a spatial resolution of 5 arc-minutes. This estimation is by far the most detailed data for VWC in China. To our best knowledge, the VWC of other food items has not been studied in such a comprehensive way.

The accuracy of the water requirement for food calculated here largely depends on the reliability of the statistical data on food consumption patterns in the FAO's food balance sheets. The food balance sheets are combined every year by FAO by collecting statistical data from its member countries. The quality of the statistics collected differs among countries. For example, it has been reported that the Chinese meat consumption may be understated in the statistics largely due to the inadequately accounting for away-from-home consumption and the underestimation for the migrant workers 
living in urban areas (Fuller et al., 1999). If this is true, the current water requirement for food consumption is underestimated. An improvement in the quality of the statistical data will no doubt decrease the uncertainty of our calculation.

We acknowledge that the scenario analysis presented in this paper is rather simplified. The society is much more complex than what we have assumed. For example, consumption of animal products may be affected by prices and trade policies, which have not been taken into consideration. Or, future production of animal products such as pork may rely more on maize than in the past. This issue has been disregarded in view of the difficulty to obtain reliable data. Nevertheless, we have made a first attempt to analyze the effect of food consumption pattern on water requirement and we conclude that this influence is substantial under all scenarios.

Although this study focused on China, the impact of the developments studied will have a bearing on water cycles world-wide. As soon as China starts to import "virtual" water, it will certainly impact food prices and production systems in the rest of the world. Moreover, the development sketched in this paper may be exemplary for developments which are likely to occur elsewhere, more particularly on the Indian sub-continent, Africa and South America, where similar dietary changes are taking place. If, in addition, we consider the water demands associated with the expected large scale production of biofuel (e.g. Uhlenbrook, 2007), then considerable changes in the hydrological cycle are likely to occur, worldwide.

Acknowledgements. This study was supported by the European Commission within the GEO-BENE project framework (Global Earth Observation - Benefit Estimation: Now, Next and Emerging, Proposal No 037063). Special thanks are also given to A. J. B. Zehnder and H. Yang for their supervision of Junguo Liu's $\mathrm{PhD}$ study. We also thank Nick van de Giesen (Delft University of Technology, the Netherlands), Jikun Huang (Chinese Academy of Sciences), Studer Christoph (University of Applied Sciences, Switzerland) and Hans-Peter Arp (Norwegian Geotechnical Institute) for their valuable comments and suggestion. Last but not least, we thank the four anonymous reviewers for their thorough review and constructive comments with which we could greatly improve our manuscript.

Edited by: M. Sivapalan

\section{References}

Alcamo, J., Henrichs, T., and Rösch, T.: World water in 2025: Global modeling and scenario analysis for the world commission on water for the 21st century, Report A0002, Center for Environmental Systems Research, University of Kassel, Kassel, Germany, 2000.

Allan, J. A.: Virtual water: A strategic resource global solutions to regional deficits, Ground Water, 36, 545-546, 1998.
Chapagain, A. K., and Hoekstra, A. Y.: Water footprints of nations, Value of Water Research Report Series No. 16, UNESCO-IHE, Delft, the Netherlands, 2004.

Chapagain, A. K., Hoekstra, A. Y., and Savenije, H. H. G.: Water saving through international trade of agricultural products, Hydrol. Earth Syst. Sci., 10, 455-468, 2006,

http://www.hydrol-earth-syst-sci.net/10/455/2006/.

Christopher, L. D., Courbois, C. B., and Rosegrant, M. W.: Global food demand and the contribution of livestock as we enter the new millennium, International Food Policy Research Institute, Washington, D.C., 1998.

Du, S., Mroz, T. A., Zhai, F., and Popkin, B. M.: Rapid income growth adversely affects diet quality in china-particularly for the poor!, Soc. Sci. Med., 59, 1505-1515, 2004.

Falkenmark, M.: Freshwater as shared between society and ecosystems: From divided approaches to integrated challenges, Philos. Trans. R. Soc. Lond. B. Biol. Sci., 358, 2037-2049, 2003.

FAO: FAO statistical databases: http://faostat.fao.org/default.aspx, last ccess: 10 October 2006, 2006.

Fuller F., Hayes D., and Smith D.: Reconciling Chinese meat production and consumption data, Econ. Dev. Cult. Change, 49(1), 23-43, 2000.

Gerbens-Leenes, P. W. and Nonhebel, S.: Consumption patterns and their effects on land required for food, Ecol. Econ., 42, 185-199, 2002.

Gleick, P. H.: Basic water requirements for human activities: Meeting basic needs, Water Int., 21, 83-92, 1996.

Gumbo, B.: Short-cutting the phosphorus cycle in urban ecosystems. Taylor and Francis Group, London, 320 pp., 2005.

Heilig, G. K.: Chinafood. Can china feed itself? IIASA, Laxenburg, Austria, 1999.

Hoekstra, A. Y. and Chapagain, A. K.: Water footprints of nations: water use by people as a function of their consumption pattern, Water Resour Manag, 21(1), 35-48, 2007.

Hoekstra, A. Y. and Hung, P. Q.: Globalisation of water resources: International virtual water flows in relation to crop trade, Glob. Environ. Change A., 15(1), 45-56, 2005.

Hsu, H. H., Chern, W. S., and Gale, F.: How will rising income affect the structure of food demand? in: China's food and agriculture: Issues for the 21st century, edited by: Gale, F., Economic research service/USDA, Washington, DC, 2002.

Huang, J., Rozell, S., and Rosegrant, M. W.: China's food economy to the twenty-first century; supply, demand, and trade, Econ Devel Cult Change, 47, 737-766, 1999.

Koudstaal, R., Rijsberman, F. R., and Savenije, H. H. G.: Water and sustainable development, Nat. Resour. Forum, 16, 277-290, 1992.

Liu, C. and Yin, R.: Poverty dynamics revealed in production performance and forestry in improving livelihoods: The case of west Anhui, China, For. Policy Econ., 6, 391-401, 2004.

Liu, J.: Modelling global water and food relations; development and application of a GIS-based EPIC model. Dissertation ETH No. 17069, Swiss Federal Institute of Technology, Zürich, 2007.

Liu, J. and Savenije, H. H. G.: Time to break the silence around virtual-water imports. Nature, 453, 587, 2008.

Liu, J., Wiberg, D., Zehnder, A. J. B., and Yang, H.: Modelling the role of irrigation in winter wheat yield, crop water productivity, and production in China. Irrig Sci, 26(1), 21-33, 2007a.

Liu, J., Williams, J. R., Zehnder, A. J. B., and Yang, H.: GEPIC 
- modelling wheat yield and crop water productivity with high resolution on a global scale, Agric. Sys., 94, 478-493, $2007 \mathrm{~b}$.

Liu, J., Zehnder, A. J. B., and Yang, H.: Historical trends in china's virtual water trade, Water Int, 32, 78-90, 2007c.

Makurira, H., Savenije, H. H. G., Uhlenbrook, S., Rockström, J., and Senzanje, A.: Towards a better understanding of water partitioning processes for improved smallholder rainfed agricultural systems: A case study of Makanya catchment, Tanzania. Phys. Chem. Earth, 32, 1082-1089, 2007.

MWR: China water resources bulletins, Ministry of Water Resources, Beijing, http://www.mwr.gov.cn/, 2005.

Ngigi, S. N., Rockström, J., and Savenije, H. H. G.: Assessment of rainwater retention in agricultural land and crop yield increase due to conservation tillage in Ewaso Ng'iro river basin, Kenya, Phys. Chem. Earth, 31, 910-918, 2006.

Oki, T. and Kanae, S.: Global hydrological cycles and world water resources, Science, 313, 1068-1072, 2006.

Postel, S. L., Daily, G. C., and Ehrlich, P. R.: Human appropriation of renewable fresh water, Science, 271, 785-788, 1996.

Raskin, P., Gleick, P., Kirshen, P., Pontius, G., and Strzepek, K.: Water futures: Assessment of long-range patterns and prospects, Stockholm Environment Institute, Stockholm, Sweden, 1997.

Renault, D. and Wallender, W. W.: Nutritional water productivity and diets, Agric Water Manag, 45, 275-296, 2000.

Rijsberman, F. R.: Water scarcity: Fact or fiction? Agric Water Manag, 80, 5-22, 2006.

Rockström, J.: Water for food and nature in drought-prone tropics: Vapour shift in rain-fed agriculture, Philos. Trans. R. Soc. Lond. B. Biol. Sci., 358, 1997-2009, 2003.

Rockström, J., Folke, C., Gordon, L., Hatibu, N., Jewitt, G., de Vries, F.P., Rwehumbiza, F., Sally, H., Savenije, H., and Schulze, R.: A watershed approach to upgrade rainfed agriculture in water scarce regions through Water System Innovations: an integrated research initiative on water for food and rural livelihoods in balance with ecosystem functions, Phys. Chem. Earth, 29(15-18), 1109-1118, 2004.

Savenije, H. H. G.: Water scarcity indicators; the deception of the numbers, Phys Chem Earth, 25, 199-204, 2000.

Savenije, H. H.G.: The importance of interception and why we should delete the term evapotranspiration from our vocabulary. Hydrological Processes, 18(8), 1507-1511, 2004.

Seckler, D., Amarasinghe, U., Molden, D. J., de Silva, R., and Barker, R.: World water demand and supply, 1990 to 2025: Scenarios and issues, IWMI research report 19, IWMI Research Report 19, IWMI, Colombo, Sri Lanka, 1998.
Shiklomanov, I. A.: The world's water resources, in: Proceedings of the international symposium to commemorate 25 years of the ihp, UNESCO/IHP, Paris, France, 93-126, 1991.

Steen. P.: Phosphorus availability in the 21st Century: management of a nonrenewable resource, Phosphorus and Potassium Journal, 217, 1998. (available from: http://www.nhm.ac.uk/research-curation/projects/ phosphate-recovery/p\&k217/steen.htm)

Tan, M., Li, X., Xie, H., and Lu, C.: Urban land expansion and arable land loss in china-a case study of beijing-tianjin-hebei region, Land Use Policy, 22, 187-196, 2005.

United Nation: World population prospects: The 2006 revision, United Nations, New York, 2006.

Uhlenbrook S.: Biofuel and water cycle dynamics: what are the related challenges for hydrological processes research? Hydrol Process, 21 (26): 3647-3650, 2007.

Vörösmarty, C. J., Green, P., Salisbury, J., and Lammers, R. B.: Global water resources: Vulnerability from climate change and population growth, Science, 289, 284-288, 2000.

World Bank: China 2020 - at china's table. Food security options, World Bank, Washington, D.C., 1997.

Xu, F. A. and Zhao, B. Z.: Development of crop yield and water use efficiency in fengqiu county, china, Acta Pedologica Sinica, 38, 491-497, 2001.

Yang, H. and Zehnder, A. J. B.: China's regional water scarcity and implications for grain supply and trade, Environ. Plann. A., 33, 79-95, 2001.

Yang, H., Reichert, P., Abbaspour, K. C., and Zehnder, A. J. B.: A water resources threshold and its implications for food security, Environ. Sci. Technol., 37, 3048-3054, 2003.

Zhang, D.: Virtual water trade in China with a case study for the Heihe river basin, MSc thesis, UNESCO-IHE, Delft, the Netherlands.

Zhao, S. L., Li, F. R., and Wang, J.: On the development of water harvesting agriculture in the semiarid area northwest china, Acta Bot. Boreal. Occident. Sin, 15, 9-13, 1995.

Zimmer, D. and Renault, D.: Virtual water in food production and global trade: Review of methodological issues and preliminary results, in: Virtual water trade. Proceedings of the international expert meeting on virtual water trade, edited by: Hoekstra, A. Y., UNESCO-IHE, Delft, the Netherlands, 25-47, 2003. 